\title{
Clinical audit of COPD in outpatient respiratory clinics in Spain: the EPOCONSUL study
}

\author{
This article was published in the following Dove Press journal: \\ International Journal of COPD \\ 25 January 2017 \\ Number of times this article has been viewed
}

\author{
Myriam Calle Rubio ${ }^{1-3}$ \\ Bernardino Alcázar \\ Navarrete ${ }^{4}$ \\ Joan B Soriano ${ }^{5}$ \\ Juan J Soler-Cataluña ${ }^{6}$ \\ José Miguel Rodríguez \\ González-Moro ${ }^{7}$ \\ Manuel E Fuentes Ferrer ${ }^{2,3,8}$ \\ José Luis López-Campos ${ }^{9}$ \\ On behalf of the \\ EPOCONSUL Study
}

'Pulmonary Department, Hospital Clínico San Carlos, ${ }^{2}$ Department of Medicine, Faculty of Medicine, University Complutense of Madrid, ${ }^{3}$ Research Institute of Hospital Clínico San Carlos (IdISSC), Madrid, ${ }^{4}$ Pulmonary Department, Hospital de Alta Resolución de Noja, Granada, ${ }^{5}$ Research Institute of Hospital University La Princesa (IISP), University Autónoma of Madrid, ' ${ }^{6}$ ulmonary Department, Hospital de Arnau de Villanova, Valencia, ${ }^{7}$ Pulmonary Department, Hospital Universitario Principe de Asturias, Alcalá de Henares, Madrid, ${ }^{8} \mathrm{UGC}$ of Preventive Medicine and Research Institute of Hospital Clínico San Carlos, Madrid, ${ }^{9}$ Pulmonary Department, Hospital University Virgen del Rocio, Institute of Biomedicine of Sevilla (IBiS), Sevilla, Spain

Correspondence: Myriam Calle Rubio Pneumology Department, Hospital Clínico San Carlos, C/Martin Lagos s/n, Madrid 28040, Spain

Tel/fax +34 9l 3303477

Email mcallerubio@gmail.com
Background: Chronic obstructive pulmonary disease (COPD) outpatients account for a large burden of usual care by respirologists. EPOCONSUL is the first national clinical audit conducted in Spain on the medical care for COPD patients delivered in outpatient respiratory clinics. We aimed to evaluate the clinical interventions and the degree of adherence to recommendations in outpatients of current COPD clinical practice guidelines.

Methodology: This is an observational study with prospective recruitment (May 2014-May 2015) of patients with a COPD diagnosis as seen in outpatient respiratory clinics. The information collected was historical in nature as for the clinical data of the last and previous consultations, and the information concerning hospital resources was concurrent.

Results: A total of 17,893 clinical records of COPD patients in outpatient respiratory clinics from 59 Spanish hospitals were evaluated. Of the 5,726 patients selected, 4,508 (78.7\%) were eligible. Overall, $12.1 \%$ of COPD patients did not fulfill a diagnostic spirometry criteria. Considerable variability existed in the available resources and work organization of the hospitals, although the majority were university hospitals with respiratory inpatient units. There was insufficient implementation of clinical guidelines in preventive and educational matters. In contrast, quantitative evaluation of dyspnea grade (81.9\%) and exacerbation history $(70.9 \%)$ were more frequently performed. Only $12.4 \%$ had COPD severity calculated according to the Body mass index, airflow Obstruction, Dyspnoea and Exercise capacity (BODE) index. Phenotype characteristics according to Spanish National Guideline for COPD were determined in $46.3 \%$ of the audited patients, and the risk evaluation according to Global initiative for chronic Obstructive Lung Disease was estimated only in $21.9 \%$.

Conclusion: The EPOCONSUL study reports the current situation of medical care for COPD patients in outpatient clinics in Spain, revealing its variability, strengths, and weaknesses. This information has to be accounted for by health managers to define corrective strategies and maximize good clinical practice.

Keywords: chronic obstructive pulmonary disease, clinical audit, medical care, adherence, clinical guidelines

\section{Introduction}

There are a number of clinical practice guidelines $(\mathrm{CPG})$ aimed to systemize the medical care in chronic obstructive pulmonary disease (COPD), ${ }^{1-5}$ and quality standards of care for COPD patients. ${ }^{6,7}$ However, their real-life implementation is far from perfect. Different studies have reported considerable variability in COPD medical care between different professionals, hospitals, and countries, ${ }^{8-12}$ and frequent inconsistencies with CPG recommendations. ${ }^{13,14}$

Several clinical audits of inpatient care in COPD have been conducted in the last decade. The recent, landmark European Clinical COPD Audit ${ }^{12}$ carried out in 
13 European countries, and various initiatives at the national level (UK, ${ }^{8}$ Spain, ${ }^{9}$ and Scandinavian countries ${ }^{15}$ ), provided relevant information on unstable COPD management and its variability. However, we have less evidence surveying outpatient care, even though COPD, as a highly prevalent and chronic disease, is one of the most frequent reasons for seeking medical attention and accounts for $10 \%$ of primary care and $30 \%$ of respiratory outpatient care visits. ${ }^{16}$ Most previous studies explored single aspects, such as the diagnosis ${ }^{17}$ or the prescribing pattern, ${ }^{18-21}$ or health care database management analysis, such as the studies from Sweden ${ }^{22}$ and Finland, ${ }^{23}$ often having limited sample size of patients and/or centers. ${ }^{10,24}$ To our knowledge, no audit at the national level has been performed of outpatient specialized care in COPD.

In this study, we present the results of the EPOCONSUL study, the first national audit which evaluated the adequacy of medical care in COPD according to official Spanish guideline Spanish National Guideline for COPD (GesEPOC), and describes the material and organizational resources of outpatient respiratory clinics in Spain.

\section{Methods}

\section{Study design}

EPOCONSUL is an observational cross-sectional study with prospective case recruitment in outpatient respiratory clinics for a period of 12 months (May 2014-May 2015). The sample population was selected from patients seen for a consultation at the participating centers during the recruitment period. Recruitment was intermittent and prospective during the year, and every 2 months each investigator recruited the first 10 patients diagnosed with COPD and seen in the outpatient respiratory clinic. The inclusion criteria were patients aged $>40$ years, smokers or ex-smokers (of at least 10 pack-years) with COPD diagnosed on the basis of spirometric tests $\left(\mathrm{FEV}_{1} / \mathrm{FVC}\right.$ post-bronchodilation $<0.7$ or $\mathrm{FEV}_{1} /$ FVC pre-bronchodilation $<0.7$ and $\mathrm{FEV}_{1} \leq 80 \%$, if there is no bronchodilation reversibility testing available). The exclusion criteria were no previous follow-up for at least 1 year in a respiratory outpatient clinic and patients that currently participate in clinical trials or research projects related to COPD. The information gathered was historical in nature as for the clinical data of the last and previous consultations, where the information about hospital resources was concurrent.

\section{Study organization and participating hospitals}

A Scientific Committee made up of pulmonologists and epidemiologists designed the study, determined the variables, coordinated the work process, and data analysis. A company specialized in information services and consulting for the health care sector (IMS Health, Madrid, Spain) was in charge of supervising the database and the work of the local investigators.

There was an official invitation to participate in the study from the Spanish Society of Pneumology and Thoracic Surgery to all the respiratory units in Spain with respiratory outpatient clinics according to the 2012 Registry of the Ministry of Health. From the 175 public hospitals in the National Health System invited, 59 participated (33.3\%). The catchment population was estimated for each Autonomous Community of Spain from the catchment population assigned to each participating hospital according to population census data of 2015. The participating hospitals and investigators are detailed in Supplementary material S1.

\section{Patient selection}

Clinical records of all patients scheduled for visit in the outpatient respiratory clinic on the assigned day (the first working day of every second month) were selected for review. Subsequently, patients identified as diagnosed with COPD were reevaluated to determine if they met the inclusion/exclusion criteria. The sampling process is described in a Strengthening the reporting of observational studies in epidemiology flow chart (Figure 1). ${ }^{25}$

\section{Variables selection}

The Scientific Committee elaborated a preliminary version of the Case Report Form that was shared and discussed with a panel of local pulmonologists and investigators in a face-to-face meeting and subsequently, via email. The final questionnaire contained 46 hospital-oriented and 153 patient-oriented variables, all described in Supplementary material S2. The variables were separated in 3 groups: 1) on available resources and work organization; 2) on patient characteristics; and 3) on clinical practice models: interventions undertaken during the consultation, and at the last audited visit.

The degree of current CPG implementation of the main statements according to GesEPOC $2012^{3}$ and strategy Global initiative for chronic Obstructive Lung Disease (GOLD) $2013^{2}$ were evaluated as described in Supplementary material S3.

\section{Data acquisition and processing protocol} At the beginning of the study the investigators completed a questionnaire about their hospital, and the resources and work process in their respective outpatient respiratory clinic. 


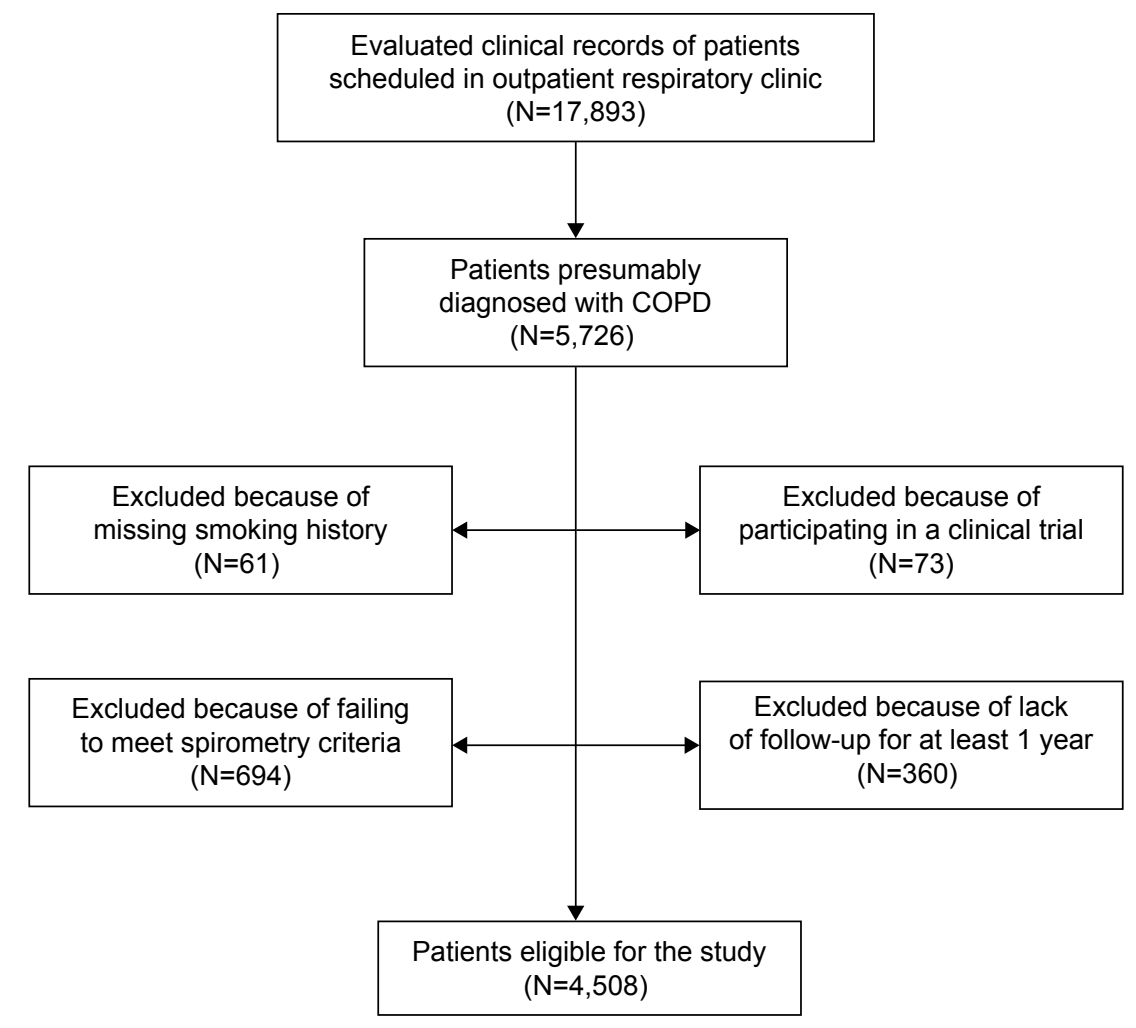

Figure I Strengthening the reporting of observational studies in epidemiology flow chart of the sampling process.

Abbreviation: COPD, chronic obstructive pulmonary disease.

To preserve the blinding of the clinical performance evaluation, the investigators were not the treating physicians of the study cases.

The database was externally checked on a daily basis to identify errors, inconsistent and missing values. Values considered extreme or inconsistent with other related values were returned to the local investigators for verification and modification as needed.

\section{Ethical aspects}

The protocol was approved by the Ethics Committee of the Hospital Clínico San Carlos (Madrid, España; internal code 14/030-E), certifying that it complied with the ethical principles formulated in the Declaration of Helsinki regarding medical research and preservation of the confidentiality of patient data. Current research laws in Spain (Ley be Investigación Biomédica de 2007 and Ley de Protección de Datos de 1999) explicitly state there is no need of either Ethics Review Board approval or individual consent for retrospective assessments of data obtained from usual clinical care for audit and research purposes, such as in our study. The protocol was also approved by the local Ethics Committee of every participating hospital.

To avoid modifications of the usual clinical practice and preserve the blinding of the clinical performance evaluation, the medical staff were not informed about the audit. Patient data were coded and their confidentiality preserved according to Spain's law regulations. The Scientific Committee had the responsibility to guarantee the scientific and methodological accuracy of the study, and the quality control of all data collected.

\section{Statistical analysis}

Descriptive results are presented both at patient level and on hospital level. Qualitative variables are presented by absolute and relative frequency (\%). The quantitative variables are summarized as median, interquartile range (IQR) and minimum-maximum. Significance of variability by area/ hospital was explored by Kruskal-Wallis or chi-square tests, depending on the nature of the variable between the different participant centers. Data were processed using the the Statistical Package SPSS, version 15.0. $P$-values $<0.05$ were considered statistically significant.

To evaluate the degree of CPG implementation, criteria of good clinical practice and quality standards were classified into 3 categories: clinical evaluation of the patient, disease evaluation, and therapeutic interventions. The number of quality standards met on patient-level and hospital-level were analyzed in each category. 


\section{Results}

A total of 17,893 clinical records of patients attended in outpatient respiratory clinics were evaluated during the study period, and the clinical records of patients presumably diagnosed with COPD (5,726 records) were selected. Those patients who met all the inclusion and none of the exclusion criteria were 4,508 (78.7\%). The exclusion criteria are described in Figure 1.

\section{Characteristics of the participating centers}

A total of 59 centers (33.7\% of the potentially eligible) from 16 out of the 17 Spanish Autonomous Communities participated in the EPOCONSUL study (except La Rioja region with 322,000 inhabitants representing $0.68 \%$ of the total population of Spain). The catchment population assigned for the participating hospitals in every Autonomous Community is summarized in Table 1 . The estimated population covered by the EPOCONSUL study was 18,104,350 representing $\sim 39.3 \%$ of the Spanish population.

The characteristics of the participating hospitals are represented in Table 2 . The majority were university hospitals $(83.1 \%)$ and with $>20$ respiratory care beds $(83.7 \%)$. However, there was wide variability in the resources and organization of the centers.

\section{Characteristics of the audited patients}

The main characteristics of the 4,508 patients evaluated are presented in Table 3. Most of them were male (86\%), of advanced age (median of 69.7 years), and with significant comorbidities. Overall, 23\% were active smokers, and their COPD was mostly symptomatic and with severe airflow obstruction.

\section{Diagnostic procedures}

The main diagnostic procedures are described in Table 4. An important proportion of patients followed in outpatient respiratory clinics were referred by their primary care $(44.7 \%)$, already had a long follow-up period in the outpatient respiratory clinic (median 4 years; IQR 3.5-5 years) and 50.4\% were scheduled for a follow-up appointment in $<6$ months.

\section{Clinical interventions}

The main clinical interventions during the last patient consultation are summarized in Table 5. The grade of dyspnea and the exacerbation history were evaluated in most patients, $81.9 \%$ and $70.9 \%$ of them, respectively. Only $12.4 \%$ had COPD severity calculated according to the Body mass index, airflow Obstruction, Dyspnoea and Exercise capacity (BODE) index. Phenotype characteristics according to GesEPOC were determined in $46.3 \%$ of the audited patients, and the risk evaluation according to strategy Global iniciative for chronic Obstructive Lung Disease (GOLD) was estimated only in $21.9 \%$, again all with a considerable variability between centers.

\section{Adherence to current CPG}

Adherence to the main CPG statements is summarized in Table 6. All the good clinical practice standards were only applied to a small number of patients evaluated during the

Table I Participating hospitals and catchment population by Autonomous Community

\begin{tabular}{lllll}
\hline Region of Spain & $\begin{array}{l}\text { Number of } \\
\text { participating hospitals }\end{array}$ & $\begin{array}{l}\text { Population assigned } \\
\text { for admission }\end{array}$ & $\begin{array}{l}\text { Population of the } \\
\text { Autonomous Community }\end{array}$ & $\begin{array}{l}\text { Catchment population of } \\
\text { the EPOCONSUL study (\%) }\end{array}$ \\
\hline Andalucía & 10 & $2,784,083$ & $8,424,102$ & 33 \\
Aragón & 2 & 597,000 & $1,346,293$ & 44.3 \\
Asturias & 1 & 250,000 & $1,081,487$ & 23.1 \\
Islas Baleares & 2 & 575,000 & $1,113,114$ & 51.6 \\
País Vasco & 4 & $1,285,000$ & $2,184,606$ & 58.8 \\
Islas Canarias & 1 & 700,000 & $2,126,769$ & 32.9 \\
Cantabria & 2 & 395,000 & 66.6 \\
Castilla y la Mancha & 4 & $1,186,014$ & 593,121 & 56 \\
Castilla y León & 4 & $1,119,086$ & $2,115,334$ & 22.7 \\
Cataluña & 5 & $1,657,000$ & $2,558,463$ & 24.7 \\
Extremadura & 1 & 273,977 & $7,539,618$ & 34.7 \\
Galicia & 2 & 970,000 & $1,109,367$ & 53.7 \\
Madrid & 11 & $3,484,995$ & $2,795,422$ & 52.3 \\
Murcia & 3 & 770,175 & $6,489,680$ & 80.5 \\
Navarra & 1 & 517,020 & $1,470,069$ & 30 \\
Valencia & 6 & $1,540,000$ & 642,051 & 39.3 \\
Total & 59 & $18,104,350$ & $5,117,190$ & $46,064,635$ \\
\hline
\end{tabular}

Notes: Data are presented as numbers. The percentages refer to the total population number. There was no participating hospital in La Rioja, the I7th Autonomous Community in Spain. 
Table 2 Characteristics of the participating hospitals and the resources of the respiratory units $(\mathrm{N}=59)$

\begin{tabular}{|c|c|c|c|c|}
\hline Variables & $\%$ & Median & IQR & Min-Max \\
\hline Public University Hospital & 83.1 & & & \\
\hline Inpatient respiratory clinic available & 83.1 & & & \\
\hline $\begin{array}{l}\text { Number of inpatient respiratory } \\
\text { beds } \geq 20 \text { beds }\end{array}$ & 83.7 & 30 & $20-35.5$ & $10-66$ \\
\hline \multicolumn{5}{|l|}{ Number of pulmonology staff members } \\
\hline$\geq 5$ staff & 81.4 & 10 & $5-13$ & $1-28$ \\
\hline Pulmonology residents present & 67.8 & 4 & $3.25-8$ & $1-12$ \\
\hline \multicolumn{5}{|c|}{ Minutes of first time general respiratory outpatient visit } \\
\hline$<15$ & 6.8 & 20 & $15-30$ & $10-60$ \\
\hline $15-19$ & 33.9 & & & \\
\hline$\geq 20$ & 59.3 & & & \\
\hline \multicolumn{5}{|c|}{ Minutes of follow-up general respiratory outpatient visit } \\
\hline$\leq 10$ & 47.5 & 12 & $10-15$ & $5-60$ \\
\hline $11-14$ & 8.5 & & & \\
\hline$\geq 15$ & 44.1 & & & \\
\hline $\begin{array}{l}\text { Nursing respiratory outpatient } \\
\text { clinic available }\end{array}$ & 45.8 & & & \\
\hline $\begin{array}{l}\text { Specialized COPD outpatient } \\
\text { clinic available }\end{array}$ & 47.5 & & & \\
\hline \multicolumn{5}{|c|}{ Minutes of first time specialized COPD outpatient visit } \\
\hline$<15$ & 3.4 & 20 & $15-30$ & $1-60$ \\
\hline $15-19$ & 21.7 & & & \\
\hline$\geq 20$ & 72.9 & & & \\
\hline \multicolumn{5}{|c|}{ Minutes of follow-up general respiratory outpatient visit } \\
\hline$\leq 10$ & 30.5 & 15 & $10-15$ & $0-60$ \\
\hline $11-14$ & 5 & & & \\
\hline$\geq 15$ & 64.4 & & & \\
\hline Nurse available in specialized & 27.5 & & & \\
\hline \multicolumn{5}{|l|}{ COPD outpatient clinic } \\
\hline \multicolumn{5}{|c|}{ Functional respiratory laboratory available } \\
\hline Spirometry & 100 & & & \\
\hline Diffusing capacity & 100 & & & \\
\hline Plethysmography & 100 & & & \\
\hline Respiratory muscle strength & 84.7 & & & \\
\hline 6MWT available & 94.9 & & & \\
\hline $\begin{array}{l}\text { Inhalation technique } \\
\text { educational program available }\end{array}$ & 30.5 & & & \\
\hline $\begin{array}{l}\text { Cardiopulmonary exercise } \\
\text { testing available }\end{array}$ & 62.7 & & & \\
\hline $\begin{array}{l}\text { Respiratory rehabilitation } \\
\text { program available }\end{array}$ & 74.6 & & & \\
\hline Hospital-based & 61.4 & & & \\
\hline Home-based & 6.8 & & & \\
\hline Mixed & 31.8 & & & \\
\hline $\begin{array}{l}\text { Alfa-I-antitrypsin genetic } \\
\text { testing available }\end{array}$ & 67.8 & & & \\
\hline $\begin{array}{l}\text { Written COPD } \\
\text { nutritional protocol available }\end{array}$ & 13.0 & & & \\
\hline Sputum eosinophil count available & 44.1 & & & \\
\hline
\end{tabular}

Note: Data are represented as percentages.

Abbreviations: COPD, chronic obstructive pulmonary disease; IQR, interquartile range (on hospital-level); 6MWT, 6-minute walk test.

study. However, there was a better adherence to the statements in the clinical evaluation category, with 3 out of 6 evaluated good clinical practice criteria met in $65.5 \%$ of the patients. On the contrary, CPG implementation was inferior in the disease characteristics category, with 4 out of 8 evaluated criteria met in only $30.1 \%$ of patients; again, with considerable variability between centers (median 27\%; IQR 13.3\%-48.8\%). The poorest adherence to the quality standards was observed in the therapeutic interventions category, with only $22.4 \%$ of the subjects fulfilling 3 out of 5 criteria. Overall, only $18.3 \%$ of patients fulfilled all 6 criteria at the first clinical evaluation; $1.5 \%$ of patients fulfilled all 8 criteria at the COPD evaluation; and $9.3 \%$ of patients fulfilled all 5 criteria at the therapeutic intervention.

\section{Discussion}

This work describes the adherence to current medical care guidelines for COPD in outpatient respiratory clinics in Spain. To our knowledge, this is the first national audit in this setting. Although clinical interventions in COPD have been evaluated in previous works, different to our study, they involve small samples of patients or hospitals, ${ }^{10,24}$ or deal with specific aspects of COPD care. ${ }^{17-20}$

Clinical audits have been traditionally used in health care as a tool to collect information about the care delivered and, accordingly, as a process for quality improvement. They help to identify the problem areas and offer extremely valuable information for health care professionals and administrators, both focused on a clinical practice that complies with quality standards. Communicating results to the health professionals has been regarded as a strategy for self-correction of their clinical practice. ${ }^{26,27}$ In this context, the present study attempts to raise awareness about the need to improve outpatient clinical care in COPD and to serve as a starting point for pulmonologists and health care administrators to analyze the detected deficiencies in COPD outpatient care, and consider corrective interventions.

Our study has several strengths and limitations. The main strength is its sample size and representativity, being a nationwide study with regional representation, and the sequential data collection over 1 year using a standardized protocol which avoided seasonal bias and prevented the inclusion of cases without a reliably established COPD diagnosis. A study with such population coverage should provide information on the adherence to the Spanish guideline GesEPOC and to the patterns of diagnosis and treatment with the GOLD strategy and offers a quite realistic picture of the clinical characteristics of the COPD patient, the usual clinical practice models, the available resources and the work organization in Spanish Respiratory units. Furthermore, most centers are university hospitals with respiratory inpatient clinics and pulmonology residents, but 
Table 3 Descriptive data of the evaluated patients at both patient and hospital level

\begin{tabular}{|c|c|c|c|c|c|}
\hline \multirow[t]{2}{*}{ Variables } & \multicolumn{2}{|c|}{ Patients $(\mathrm{N}=4,508)$} & \multicolumn{3}{|c|}{ Hospitals ( $\mathbf{N}=59)$} \\
\hline & $\mathbf{N}$ & Percent or median (IQR) & Median & IQR & Min-Max \\
\hline Gender (male, \%) & 4,508 & 86 & 87.5 & $82.1-93.2$ & $60-100$ \\
\hline Age (years) & 4,508 & $69.7(63-77.7)$ & 70 & $69-72$ & $64-76.5$ \\
\hline$\leq 55$ & & 8.5 & 8.2 & $5.8-11.7$ & I.7-33.3 \\
\hline $56-69$ & & 38.7 & $38.1 \%$ & $30-42.6$ & $16.6-58.2$ \\
\hline$\geq 70$ & & 52.8 & 53.3 & $47.1-61.7$ & $31.7-78.3$ \\
\hline Pack-years & 4,508 & $47(34-70)$ & 45 & $40-51$ & $10-190$ \\
\hline Active smokers (\%) & 4,508 & 23.1 & 22 & $18-29$ & $6.5-37.5$ \\
\hline BMI $\left(\mathrm{kg} / \mathrm{m}^{2}\right)$ & 4,499 & $28.0(24.4-31.1)$ & 27.8 & $26.6-28.5$ & $24.3-30.5$ \\
\hline$\leq 21$ & & 7.1 & 6.7 & 4.1-9.2 & $0-20$ \\
\hline$\geq 30$ & & 32.1 & 31.4 & $26.2-37.7$ & $10.1-66.7$ \\
\hline Charlson index & 4,508 & $2(I-4)$ & 2 & $2-3$ & $1-9$ \\
\hline$\geq 3$ & 4,508 & 44.9 & 44.5 & $40-56.6$ & $20-78.3$ \\
\hline Dyspnea $(\mathrm{mMRC}) \geq 2$ & 3,099 & 60.2 & 61.1 & $46.3-76.2$ & $20-100$ \\
\hline CAT questionnaire $>10$ & 869 & 62.4 & 64 & $47.9-83.8$ & $0-100$ \\
\hline Chronic bronchitis criteria & 4,508 & 41.7 & $4 I$ & $28.3-51$ & $0-85.5$ \\
\hline Chronic colonization & 4,508 & 6.0 & 5 & $3.2-8.3$ & $0-27$ \\
\hline Symptoms suggestive of asthma & 4,508 & 26.5 & 18.3 & $10.8-35$ & $0-95$ \\
\hline $\mathrm{FEV}_{1}(\%)$ & 4,508 & $52.4(38-65)$ & 52 & $49-55$ & $36-71$ \\
\hline$<30$ & & 10.5 & 9.6 & $5-13.5$ & $0-27.2$ \\
\hline$\geq 30-<50$ & & 35.4 & 35.7 & $29.3-40.5$ & $0-65.3$ \\
\hline$\geq 50-<80$ & & 46.8 & 48.4 & $41.3-56.9$ & $25-100$ \\
\hline$\geq 80$ & & 7.3 & 5.1 & $0-10.7$ & $0-20$ \\
\hline Bronchodilator reversibility (\%) & 2,809 & $9.7(3-13)$ & 7 & $5-9$ & $1-14$ \\
\hline Number of moderate/severe exacerbations in the last year & 3,196 & I.I (0-2) & I & $0-1$ & $0-3$ \\
\hline Number of hospital admissions in the last year & 2,851 & $0.5(0-1)$ & 0 & $0-0$ & $0-2$ \\
\hline BODE value & 632 & $3.9(3-5)$ & 4.5 & $3-5.5$ & $\mathrm{I}-8$ \\
\hline BODEx value & 321 & $3.4(2-5)$ & 3.5 & $3-5$ & $\mathrm{I}-7.5$ \\
\hline \multicolumn{6}{|l|}{ GOLD group } \\
\hline A & 985 & 22.7 & 14.3 & $0-25.9$ & $0-66.7$ \\
\hline B & & 18.7 & 16.7 & $0-24.1$ & $0-100$ \\
\hline $\mathrm{C}$ & & 18.7 & 20 & $9.8-33.3$ & $0-62.5$ \\
\hline $\mathrm{D}$ & & 39.9 & 40 & $23.5-55.6$ & $0-100$ \\
\hline \multicolumn{6}{|l|}{ GesEPOC phenotype } \\
\hline Non-exacerbator & 2,086 & 44.4 & 41.7 & $27.4-54.3$ & $0-100$ \\
\hline Exacerbator with chronic bronchitis & & 22.6 & 21.1 & $9.7-29.7$ & $0-51.9$ \\
\hline Exacerbator with emphysema & & 18.1 & 16.7 & $1 \mathrm{I} .1-23.5$ & $0-100$ \\
\hline ACOS & & 14.9 & 14.3 & $8.7-22.2$ & $0-75$ \\
\hline LAMA monotherapy & 4,391 & 10.0 & 10 & $4.8-15.3$ & $0-33$ \\
\hline LAMA-LABA combination & 4,391 & 22.7 & 20.3 & |4.5-27.9 & $8.5-71.4$ \\
\hline LABA + CSI combination & 4,391 & 7.7 & 6.7 & $3.4-9.8$ & $0-29$ \\
\hline Triple therapy (LAMA + LABA + CSI) & 4,391 & 49.1 & 50.8 & $39.3-60.3$ & $0-71.2$ \\
\hline Long-term oxygen therapy & 4,508 & 26.6 & 25 & $17.1-33.3$ & $0-53$ \\
\hline Home ventilation & 4,508 & 7.5 & 5 & $2.5-11.6$ & $0-100$ \\
\hline Respiratory rehabilitation & 4,508 & 9 & 5 & $0-11.8$ & $0-46.7$ \\
\hline
\end{tabular}

Note: Average value expressed as the mean (standard deviation) or absolute (relative) frequency depending on the nature of the variable.

Abbreviations: BMI, body mass index; CAT, COPD assessment test; CSI, inhaled corticosteroids; GesEPOC, Spanish National Guideline for COPD; GOLD, Global initiative for chronic Obstructive Lung Disease; IQR, interquartile range; LABA, long-acting beta-2 agonists; LAMA, long-acting antimuscarinic agents; mMRC, modified Medical Research Council; BODEx index, body mass index, airflow obstruction, dyspnoea and exacerbations; ACOS, ACOS asthma-COPD overlap syndrome; BODE, body mass index, airflow obstruction, dyspnoea and exercise capacity.

with differences in the available resources and work organization between the participating hospitals, for example, the number of pulmonology staff members, inpatient beds or the availability of a specialized COPD outpatient clinic. This way our study provides novel information relating to the degree of actual compliance guidelines with available resources and clinical presentation.

Nevertheless, there are some limitations that have to be considered. First, the selection of participating centers was not random; they were selected based on their previous 
Table 4 Diagnostic procedures conducted during the follow-up at both patient- and hospital-level

\begin{tabular}{|c|c|c|c|c|c|c|}
\hline \multirow[t]{2}{*}{ Variables } & \multicolumn{2}{|c|}{ Patients $(\mathrm{N}=4,508)$} & \multicolumn{3}{|c|}{ Hospitals ( $\mathbf{N}=\mathbf{5 9})$} & \multirow[t]{2}{*}{$P$-value* } \\
\hline & $\mathbf{N}$ & $\begin{array}{l}\text { Percent or } \\
\text { median (IQR) }\end{array}$ & Median & IQR & Min-Max & \\
\hline Bronchodilator reversibility testing & 4,508 & 86 & 65 & $50-85$ & $0-98.3$ & $<0.001$ \\
\hline Arterial blood gases measured on any occasion & 4,508 & 63.9 & 67.5 & $49.2-81.7$ & $25-100$ & $<0.001$ \\
\hline Alfa-I-antitrypsin serum testing levels available & 4,508 & 22.1 & 17.5 & $7.9-30$ & $0-69.4$ & $<0.001$ \\
\hline Lung volumes measured on any occasion & 4,508 & 42.8 & 43.3 & $19.7-65$ & $0-99.2$ & $<0.001$ \\
\hline Diffusion capacity measured on any occasion & 4,499 & 49 & 55 & $28.3-67.8$ & $0-92.1$ & $<0.001$ \\
\hline 6MWT carried out on any occasion & 4,508 & 27.3 & 22.5 & $8.3-48.3$ & 0-93.3 & $<0.001$ \\
\hline Cardiopulmonary exercise testing carried out on any occasion & 3,099 & 3.7 & 3.3 & $0-5$ & $0-19.7$ & $<0.001$ \\
\hline BODE index calculated on any occasion & 869 & 14 & 5.4 & I.7-22.5 & $0-74.6$ & $<0.001$ \\
\hline CAT questionnaire evaluated on any occasion & 4,508 & 19.3 & 8.9 & I.7-35.6 & $0-100$ & $<0.001$ \\
\hline Chest CT scan carried out on any occasion & 4,508 & 58.9 & 60 & $50-71.7$ & $28.9-90.2$ & $<0.001$ \\
\hline Comorbidities identified in the clinical record & 4,508 & 81.5 & $85.7 \%$ & $78.3-91.9$ & $41.3-100$ & $<0.001$ \\
\hline \multicolumn{7}{|l|}{ Delivered to respiratory outpatient clinic from } \\
\hline Primary care & 3,594 & 44.7 & 47.2 & $27.5-56.5$ & 0-98.3 & $<0.001$ \\
\hline Emergency & & 6.9 & 6.3 & $2.2-11.5$ & $0-27.4$ & \\
\hline Department inpatient care & & 20.7 & 18 & $12-25.9$ & $0-57.5$ & \\
\hline \multicolumn{7}{|l|}{ Scheduled follow-up visits (months) } \\
\hline$<6$ & 4,386 & 50.4 & 47.4 & $39.7-59$ & $16.9-90.7$ & $<0.001$ \\
\hline $6-12$ & & 33.2 & 33.3 & $26.3-41.4$ & $8.1-6 \mid$ & \\
\hline$>12$ & & 16.4 & 13.3 & $7.4-22$ & $0-54.2$ & \\
\hline Respiratory care follow-up (years) & 4,508 & $4(2-7)$ & 4 & $3.5-5$ & $2-7.5$ & $<0.001$ \\
\hline
\end{tabular}

Notes: Average value expressed as the mean (standard deviation) or absolute (relative) frequency depending on the nature of the variable. ${ }^{*}$ Calculated for the variability between centers using test de Kruskal-Wallis or chi-square test, depending on the nature of the variable.

Abbreviations: BODE, body mass index, airflow obstruction, dyspnoea and exercise capacity; CAT, COPD assessment test; CT, computerized tomography; IQR, interquartile range; 6MWT, 6-minute walk test.

Table 5 Clinical interventions at the time of the last follow-up visit at both patient- and hospital-level

\begin{tabular}{|c|c|c|c|c|c|c|}
\hline \multirow[t]{2}{*}{ Variables } & \multicolumn{2}{|c|}{ Patients $(\mathrm{N}=4,508)$} & \multicolumn{3}{|c|}{ Hospitals ( $\mathrm{N}=\mathbf{5 9})$} & \multirow[t]{2}{*}{ P-value* } \\
\hline & $\mathbf{N}$ & $\begin{array}{l}\text { Percent or } \\
\text { median (IQR) }\end{array}$ & Median & IQR & Min-Max & \\
\hline Evaluation of dyspnea grade & 4,508 & 81.9 & 87.5 & $82.1-93.2$ & $60-100$ & $<0.001$ \\
\hline Number of moderate or severe exacerbations in the last & 4,508 & 70.9 & 73.3 & $59.5-88.3$ & $18.3-100$ & $<0.001$ \\
\hline 12 months recorded & & & & & & \\
\hline Number of hospital admissions in the last 12 months collected & 4,508 & 63.2 & 66.9 & $50.8-86.2$ & $10.8-100$ & $<0.001$ \\
\hline Data on regular exercise collected & 4,508 & 41.0 & 61.1 & $46.3-76.2$ & $20-100$ & $<0.001$ \\
\hline COPD diagnosis established in the visit report & 4,508 & 89.4 & 97.5 & $83.5-98.8$ & $40-100$ & $<0.001$ \\
\hline COPD severity defined in the report & 4,508 & 74.7 & 84.3 & $61.7-91.8$ & $3.2-100$ & $<0.001$ \\
\hline \multicolumn{7}{|l|}{ By which criteria } \\
\hline FEV & & 81.3 & 91.1 & 66.4-99 & $2.2-100$ & \\
\hline BODE & & 12.4 & 4.5 & $0-16.4$ & $0-74.5$ & \\
\hline BODEx & & 6.2 & 1.9 & $0-8.1$ & $0-62.5$ & \\
\hline GOLD-type defined in the report & 4,508 & 21.9 & 8.3 & $0.8-32.9$ & $0-91.1$ & $<0.001$ \\
\hline COPD phenotype according to GesEPOC defined in the report & 4,508 & 46.3 & 46.7 & $27.4-67.5$ & $1.7-100$ & $<0.001$ \\
\hline Current COPD treatment listed in the report & 4,508 & 95.3 & 97.5 & $93.5-99.2$ & $71.7-100$ & $<0.001$ \\
\hline Treatment adherence evaluated & 4,508 & 0 & 31.7 & $|7.9-6| .7$ & $1.7-100$ & $<0.001$ \\
\hline Inhalation technique evaluated & 4,508 & 27.1 & 44.5 & $40-56.6$ & $20-78.3$ & $<0.001$ \\
\hline Grade of satisfaction with inhalation device evaluated & 4,508 & 17.1 & 7.6 & $1.7-23.2$ & $0-100$ & $<0.001$ \\
\hline Adverse effects of medication collected & 4,508 & 22 & 12.4 & $5-27.5$ & $0-100$ & $<0.001$ \\
\hline $\begin{array}{l}\text { Specific intervention for smoking cessation in active } \\
\text { smokers offered }\end{array}$ & 2,929 & 22.4 & 20 & $10.1-27.5$ & $0-73$ & $<0.001$ \\
\hline $\begin{array}{l}\text { Have arterial blood gases been measured on any occasion } \\
\text { in patients on long-term oxygen therapy? }\end{array}$ & 1,199 & 90.2 & $95.2 \%$ & $90-100$ & $46-100$ & $<0.001$ \\
\hline Regular exercise recommended during the visit & 4,508 & 41.2 & 36.1 & $15.1-63.4$ & $0-100$ & $<0.001$ \\
\hline Influenza annual vaccination recorded & 4,508 & 42.7 & 64 & $47.9-83.8$ & $0-100$ & $<0.001$ \\
\hline Pneumococcal vaccination recorded & 4,508 & 25.3 & 41 & $28.3-5 ।$ & $0-85.5$ & $<0.001$ \\
\hline Any change in current medication advised & 4,508 & 22.5 & 5 & $3.2-8.3$ & $0-27$ & $<0.001$ \\
\hline
\end{tabular}

Notes: Average value expressed as the mean (standard deviation) or absolute (relative) frequency depending on the nature of the variable. ${ }^{*}$ Calculated for the variability between centers using test de Kruskal-Wallis or chi-square, depending on the nature of the variable.

Abbreviations: BODEx index, body mass index, airflow obstruction, dyspnoea and exacerbations; COPD, chronic obstructive pulmonary disease; GesEPOC, Spanish National Guideline for COPD; GOLD, Global initiative for chronic Obstructive Lung Disease; IQR, interquartile range. 
Table 6 Adherence to the main clinical practice guidelines statements

\begin{tabular}{|c|c|c|c|c|c|c|c|}
\hline \multirow[t]{2}{*}{$\begin{array}{l}\text { Criteria of good clinical practice evaluated } \\
\text { in EPOCONSUL }\end{array}$} & \multirow{2}{*}{$\begin{array}{l}\text { Results } \\
\text { EPOCONSUL } \\
\text { study } \\
\text { No of } \\
\text { criteria met }\end{array}$} & \multicolumn{2}{|c|}{$\begin{array}{l}\text { Patients } \\
(\mathrm{N}=4,508)\end{array}$} & \multicolumn{3}{|c|}{ Hospitals $(\mathrm{N}=59)$} & \multirow[t]{2}{*}{$P$-value ${ }^{\dagger}$} \\
\hline & & $\mathbf{N}$ & $\%$ & Median & IQR & Min-Max & \\
\hline \multicolumn{8}{|l|}{ During clinical evaluation (criteria) } \\
\hline $\begin{array}{l}\text { I. Was dyspnea grade evaluated on current visit? } \\
\text { 2. Was the number of hospital admissions in the last } 12 \text { months } \\
\text { recorded during current visit? }\end{array}$ & 6 criteria & 4,508 & 18.3 & 14.6 & $5-30$ & $0-100$ & $<0.001$ \\
\hline $\begin{array}{l}\text { 3. Was the number of moderate or severe exacerbations in the } \\
\text { last } 12 \text { months collected during current visit? }\end{array}$ & $>3$ criteria & 2,952 & 65.5 & 70.0 & $46.7-89.3$ & $11.7-100$ & $<0.001$ \\
\hline $\begin{array}{l}\text { 4. Was current smoking habit collected? } \\
\text { 5. Was regular exercise data collected during current visit? } \\
\text { 6. Are comorbidities identified in the clinical record? }\end{array}$ & $\leq 3$ criteria & I,556 & 34.5 & 30 & $10.7-53.3$ & $0-88.3$ & $<0.001$ \\
\hline $\begin{array}{l}\text { During COPD evaluation (criteria) } \\
\text { I. Alfa-I-antitrypsin serum level determination available? }\end{array}$ & & & & & & & \\
\hline $\begin{array}{l}\text { 2. COPD spirometry severity defined in the report? } \\
\text { 3. COPD GOLD type defined in the report? } \\
\text { 4. COPD phenotype according to GesEPOC defined }\end{array}$ & 8 criteria & 4,508 & 1.5 & 0 & $0-0.8$ & $0-14.6$ & $<0.001$ \\
\hline $\begin{array}{l}\text { in the report? } \\
\text { 6. 6MWT carried out on any occasion? } \\
\text { 6. Diffusion capacity measured on any occasion? }\end{array}$ & $>4$ criteria & I,355 & 30.1 & 27 & 13.3-48.8 & $0-89.3$ & $<0.001$ \\
\hline $\begin{array}{l}\text { 7. Lung volumes measured on any occasion? } \\
\text { 8. Chest CT scan carried out on any occasion in exacerbator } \\
\text { phenotype? }\end{array}$ & $\leq 4$ criteria & 3,153 & 69.9 & 73 & $51.2-86.7$ & $10.7-100$ & $<0.001$ \\
\hline $\begin{array}{l}\text { During therapeutic intervention } \\
\text { I. Current COPD treatment listed in the report? }\end{array}$ & & & & & & & \\
\hline 2. Is treatment adherence evaluated in any way? & 5 criteria & 4,508 & 9.3 & 3.3 & $0-15$ & $0-45.1$ & $<0.001$ \\
\hline $\begin{array}{l}\text { 3. Is inhalation technique evaluated in any way? } \\
\text { 4. Is Pneumococcal vaccination collected? }\end{array}$ & $>3$ criteria & $\mathrm{I}, 008$ & 22.4 & 12.5 & $2.5-40$ & $0-100$ & $<0.001$ \\
\hline 5. Is exercise advised during the visit? & $\leq 3$ criteria & 3,500 & 77.6 & 87.5 & $60-97.5$ & $0-100$ & $<0.001$ \\
\hline
\end{tabular}

Notes: Clinical practice criteria (GesEPOC and GOLD) evaluated in the study is classified into 3 categories: clinical evaluation, disease evaluation and therapeutic interventions. The number of criteria of good clinical practice met in each category was analyzed in patients evaluated. Average value expressed as the mean (standard deviation) or absolute (relative) frequency depending on the nature of the variable. ${ }^{\dagger}$ Calculated for the variability between centers using test de Kruskal-Wallis or chi-square test, depending on the nature of the variable.

Abbreviations: 6MWT, 6-minute walk test; COPD, chronic obstructive pulmonary disease; CT, computerized tomography; IQR, interquartile range; GOLD, global initiative for chronic obstructive lung disease; GesEPOC, Spanish National Guideline for COPD.

participation in clinical audits on COPD and their interest to participate. In spite of these limitations we believe that our sample is representative of the current situation in the country, given the acceptable population coverage and the representation of 16 out of 17 Autonomous Communities of Spain, except La Rioja with $0.68 \%$ of the total population. We should also remember that every clinical audit has an intrinsic limitation of missing values (not available) in spite of the inclusion methodology and the periodic supervision of the database.

When looking at the resources, the most noteworthy point is perhaps the limited number of respiratory units with nursing outpatient clinics, even among those with specialized COPD outpatient clinics. There is also an important lack of educational programs on inhalation technique despite the predominance of university hospitals with pulmonology residency programs and inpatient respiratory clinics. Another issue worth mentioning is that less than half of the centers had specialized COPD outpatient clinics. If available, they usually have waiting lists similar to those of the general respiratory outpatient clinics and they frequently do not have a supporting nurse. Given that specialized COPD outpatient clinics in COPD patient care have not demonstrated effectiveness so far, we believe that analyzing these data will provide valuable information. It is also remarkable that, in spite of the availability to perform a 6-minute walk test (6MWT) in the majority of the centers and of cardiorespiratory exercise testing, the number of tests carried out is low, which is in disagreement with current recommendations according to GesEPOC. $^{3-5}$ Only $27.3 \%$ of the audited patients in our study had performed a 6MWT, bearing in mind that most were patients with severe airflow obstruction or GOLD D group. This finding corresponds to those of previous audits explored adherence to recommendations, in spite of having minor sample size, such as the one by Nardini et al (2012, 
Campania, Italy), ${ }^{10}$ where the test was only carried out in $30.7 \%$ of the audited patients, or the one by López-Campos (2014, Andalucía, Spain), in only 9.7\%. ${ }^{24}$ The reasons for the poor use of 6MWT have not been specifically looked at, but are probably related to work organizational issues, or unit's resources limiting the accessibility of the test, or may be even related to the reluctance of health professionals to change in spite of their knowledge of CPG. At any rate, this finding should raise concern as an area for urgent change. Also, an important number of centers offer the genetic testing for alpha-1-antitrypsin deficiency (67.8\%), but its determination was carried out only occasionally, in $22.1 \%$. These data support the high rate of underdiagnosis ${ }^{28}$ of this deficiency and this seems to be due to lack of awareness among pulmonologists to request this accessible, simple, and cheap test.

Regarding the profile of the COPD patient followed in respiratory outpatient clinics, most of them have been followed for several years, with a low percentage of discharge $(5 \%)$, with severe or very severe airflow obstruction and symptomatic COPD with few exacerbations treated with triple inhalation therapy. These results are similar to those from the CHAIN cohort ${ }^{29,30}$ of COPD patients followed in respiratory outpatient clinics.

From the recommendations derived from the clinical evaluation of patients, the most complied with were dyspnea grade evaluation and exacerbation history recollection, in contrast to those related to functional and disease severity quality standards. In this context, although CPG are not protocols, it is difficult to justify why $>75 \%$ of COPD patients with long-term follow-up in respiratory clinics do not have a multidimensional disease evaluation to establish their prognosis, or why over half of patients have never had their lung volumes measured.

When exploring therapeutic interventions, we see poor implementation of educational programs and preventive measures. For example, only $22 \%$ of actively smoking COPD patients have been offered a specific cessation intervention, and pneumococcal vaccination has been offered only to $25.3 \%$. These were patients frequently on triple and quadruple therapy, yet only one-fourth of them were evaluated for correct inhalation technique. In spite of the expected availability and knowledge of CPG among pulmonologists, an important number of COPD patients do not receive the standard recommended care in outpatient clinics. Again, the variability detected between centers has to be pointed out, with differences 2- to 4-fold between the different respiratory units. It could be explained in part with the smaller number of cases in some of the centers, but could also be due to other factors, such as heterogeneity of resources and organization among centers; heterogeneity of COPD itself, and of patients' needs; and accessibility and security of data source in patient files. We think it necessary to study the possible relations between these factors, in order to deal with the next challenge, to move from data collection to better patient care, which means to define and undertake improvement strategies.

\section{Conclusion}

EPOCONSUL is the first national audit of COPD in outpatient respiratory clinics in Spain. Its results highlight the disparity between guidelines and clinical practice of health care professionals who provide care for COPD patients, with both lights and shades. It is important to remember that the clinical presentation of diseases is normally variable and that these recommendations are not always evidence-based. Also, as a retrospective study, can only evaluate the information writing in the clinical history.

Our results confirm previous studies realized with limited sample size and show significant variability in terms of the available resources and work organization, the patient characteristics and clinical practice models . Such information must be accounted for by health care professionals and administrators, in order to correct the deficiencies and establish better clinical practices.

Further clinical audits are necessary to evaluate the impact of complying with quality standards on clinically significant results, such as exacerbations and mortality.

\section{Acknowledgments}

The authors thank the investigators and the centers that participated in the EPOCONSUL study (Supplementary material S1). This study has been promoted and sponsored by the SEPAR. We thank Boehringer Ingelheim for its financial support to carry out the study. The financing entities did not participate in the design of the study, data collection, analysis, publication or preparation of this manuscript.

\section{Author contributions}

MCR, JLL-C, BAN, JBS, JJS-C, JMRG-M are the study's Scientific Committee. MEFF carried out the statistical analysis and MCR designed the study and wrote the manuscript. The rest of the authors recruited patients and reviewed the manuscript. All authors contributed toward data analysis, drafting and revising the paper and agree to be accountable for all aspects of the work.

\section{Disclosure}

The authors report no conflicts of interest in this work. 


\section{References}

1. National Institute for Health and Care Excellence (NICE). Chronic obstructive pulmonary disease: management of chronic obstructive pulmonary disease in adults in primary and secondary care (partial update); 2010. Available from: http://www.nice.org.uk/guidance/ CG101/chapter/1-Guidance. Accessed September 29, 2016.

2. Vestbo J, Hurd SS, Agusti AG, et al. Global strategy for the diagnosis, management, and prevention of chronic obstructive pulmonary disease: GOLD executive summary. Am J Respir Crit Care Med. 2013;187(4):347-365.

3. Miravitlles M, Calle M, Soler-Cataluña JJ. Fenotipos clínicos de la EPOC. Identificación, definición e implicaciones para las guías de tratamiento [Clinical phenotypes of COPD: identification, definition and implications for guidelines]. Arch Bronconeumol. 2012;48:86-98. Spanish.

4. Miravitlles M, Soler-Cataluña JJ, Calle M, et al. Guía Española de la EPOC (GesEPOC). Actualización 2014. [Spanish guideline for COPD (GesEPOC). Update 2014]. Arch Bronconeumol. 2014;50(Suppl 1):1-16. Spanish.

5. Miravitlles M, Soler-Cataluña JJ, Calle M, Soriano J. Treatment of COPD by clinical phenotypes. Putting old evidence into clinical practice. Eur Respir J. 2013;41(6):1252-1256.

6. Celli BR, MacNee W; and committee members. Standards for the diagnosis and treatment of patients with COPD: a summary of the ATS/ ERS position paper. Eur Respir J. 2004;23(6):932-946.

7. Soler-Cataluña JJ, Calle M, Cosío BG, Marín JM, Monsó E, Alfageme I; Comité de Calidad Asistencial de la SEPAR; Área de Trabajo EPOC de la SEPAR. Estándares de calidad asistencial en la EPOC. [SEPAR Quality Assistance Committee; SEPAR EPOC Work Area. Healthcare quality standards in chronic obstructive pulmonary disease]. Arch Bronconeumol. 2009;45:196-203. Spanish.

8. Roberts CM, Lowe D, Bucknall CE, Ryland I, Kelly Y, Pearson MG. Clinical audit indicators of outcome following admission to hospital with acute exacerbation of chronic obstructive pulmonary disease. Thorax. 2002; 57:137-141

9. Pozo-Rodríguez F, López-Campos JL, Álvarez-Martínez CJ, et al; AUDIPOC Study Group. Clinical audit of COPD patients requiring hospital admissions in Spain: AUDIPOC study. PLoS One. 2012;7(7):e42156.

10. Nardini S, Cicchitto G, De Benedetto F, et al. Audit on the appropriateness of integrated COPD management: the "ALT-BPCO" project. Multidiscip Respir Med. 2014;9(1):40.

11. Jones R, Roberts M. National cohort data from Sweden to the National COPD audit in England and Wales: grand designs for quality improvement. Prim Care Respir J. 2014;23(1):7-8.

12. Lopez-Campos JL, Hartl S, Pozo-Rodriguez F, Roberts CM; European COPD Audit team. Variability of hospital resources for acute care of COPD patients: the European COPD Audit. Eur Respir J. 2014;43(3):754-762.

13. Miravitlles M, Vogelmeier C, Roche N, et al. A review of national guidelines for management of COPD in Europe. Eur Respir J. 2016; 47(2):625-637.

14. Wong GW, Miravitlles M, Chisholm A, Krishnan JA. Respiratory guidelines - which real world? Ann Am Thorac Soc. 2014;11(Suppl 2): S85-S91.

15. Liaaen ED, Henriksen AH, Stenfors N. A Scandinavian audit of hospitalizations for chronic obstructive pulmonary disease. Respir Med. 2010;104(9):1304-1309.
16. Fromer L. Implementing chronic care for COPD: planned visits, care coordination, and patient empowerment for improved outcomes. Int $J$ Chron Obstruct Pulmon Dis. 2011;6:605-614.

17. Izquierdo Alonso JL, Rodríguez González-Moro JM, de Lucas Ramos P, Martín Centeno A, Gobartt Vázquez E. ¿Ha cambiado el manejo de la EPOC en España? Resultados de un estudio multicéntrico comunitario (VICE). [Has the treatment of COPD changed in Spain? Results of a community multicenter study (VICE)]. Rev Clin Esp. 2008;208:18-25. Spanish.

18. Price D, West D, Brusselle G, et al. Management of COPD in the UK primary-care setting: an analysis of real-life prescribing patterns. Intl J Chron Obstruct Pulmon Dis. 2014;9:889-904.

19. López-Campos JL, Abad Arranz M, Calero Acuña C, et al. Determinants for changing the treatment of COPD: a regression analysis from a clinical audit. Int J Chron Obstruct Pulmon Dis. 2016;11:1171-1178.

20. Susanto C, Thomas PS. Assessing the use of initial oxygen therapy in chronic obstructive pulmonary disease patients: a retrospective audit of pre-hospital and hospital emergency management. Intern Med J. 2015; 45(5):510-516.

21. Wise J. COPD care has improved but could still be better, audit finds. BMJ. 2015;350:h731.

22. Ställberg B, Janson C, Johansson G, et al. Management, morbidity and mortality of COPD during an 11-year period: an observational retrospective epidemiological register study in Sweden (PATHOS). Prim Care Respir J. 2014;23(1):38-45.

23. Kinnula VL, Vasankari T, Kontula E, Sovijarvi A, Saynajakangas O, Pietinalho A. The 10-year COPD Programme in Finland: effects on quality of diagnosis, smoking, prevalence, hospital admissions and mortality. Prim Care Respir J. 2011;20(2):178-183.

24. López-Campos JL, Abad Arranz M, Calero-Acuña C, et al. Guideline adherence in outpatient clinics for chronic obstructive pulmonary disease: results from a clinical audit. PLoS One. 2016;11(3):e0151896.

25. Von Elm E, Altman DG, Egger M, Pocock SJ, Gøtzsche PC, Vandenbroucke JP; STROBE Initiative. The strengthening the reporting of observational studies in epidemiology (STROBE) statement: guidelines for reporting observational studies. Ann Intern Med. 2007; 147(8):573-577.

26. Lusuardi M, Garuti G, Massobrio M, Spagnolatti L, Borciani N. The audit-intervention-reaudit cycle can improve diagnostic standards for chronic obstructive pulmonary disease (COPD). Intern Emerg Med.2014; 9(1):113-114.

27. Montanari U, Quadrelli D, Donato G, Mercuri M, Scorletti A, Berti F. Implementation of diagnostic accuracy for COPD (ABC Project): evaluation of a guide-line in territorial clinical practice. Recenti Prog Med. 2013;104(1):23-27.

28. Barrecheguren M, Monteagudo M, Simonet P, et al. Diagnosis of alpha-1 antitrypsin deficiency: a population-based study. Int J Chron Obstruct Pulmon Dis. 2016;11:999-1004.

29. Cosio BG, Soriano JB, López-Campos JL, et al. Distribution and outcomes of a phenotype-based approach to guide COPD management: results from the CHAIN cohort. PLoS One. 2016;11(11):e0166257.

30. Cosio BG, Soriano JB, López-Campos JL, et al. Defining the asthmaCOPD overlap syndrome in a COPD cohort. Chest. 2016;149(1): $45-52$.
International Journal of COPD

\section{Publish your work in this journal}

The International Journal of COPD is an international, peer-reviewed journal of therapeutics and pharmacology focusing on concise rapid reporting of clinical studies and reviews in COPD. Special focus is given to the pathophysiological processes underlying the disease, intervention programs, patient focused education, and self management protocols.
Dovepress

This journal is indexed on PubMed Central, MedLine and CAS. The manuscript management system is completely online and includes a very quick and fair peer-review system, which is all easy to use. Visit $\mathrm{http}: / / \mathrm{www}$. dovepress.com/testimonials.php to read real quotes from published authors. 